\title{
Predictive Factors for Requirement of Ureteral J Stenting in Ureteroscopic Treatment of Distal Ureteral Stones
}

\author{
Mehmet Oguz Sahin, MD ${ }^{1^{\mathbb{D}}}$; Volkan Sen, MD, FEBU ${ }^{\mathbb{D}}$; Bora Irer, MD ${ }^{\mathbb{D}}$; Guner Yildiz, MD ${ }^{\mathbb{D}^{\mathbb{D}}}$ \\ ${ }^{1}$ Manisa State Hospital, Department of Urology, Manisa, Turkey \\ ${ }^{2}$ Izmir Metropolitan Municipality Esrefpasa Hospital, Department of Urology, Izmir, Turkey \\ ${ }^{3}$ Dr Suat Seren Chest Diseases and Surgery Training and Research Hospital, Department of Urology, Izmir, Turkey
}

\begin{abstract}
Background: We aimed to investigate the factors predicting the need for ureteral I stent placement in the treatment of distal ureteral stones by ureteroscopy (URS).

Methods: Between January 2007 and June 2018, 550 consecutive patients who underwent URS with the diagnosis of distal ureteral stone disease were evaluated in a single center. The patients were divided into two groups as; group 1 who received a ureteral J stent, and group 2 without ureteral J stent. The two groups were compared in terms of possible preoperative, perioperative and postoperative risk factors.

Results: History of systemic disease, stone disease and extracorporeal shock wave lithotripsy (SWL) were significantly higher in group $1(P<0.001, P=0.009, P=0.016)$. The operation time was longer in group $1(P<0.001)$. The rate of impacted stones was higher in group $1(61.7 \%$ vs $15.6 \%$; $P<0.001)$. In multivariate analysis, co-morbidities, previous SWL history, presence of impacted ureteral stone and prolongation of the operation time were found to be statistically significant in predicting ureteral $J$ stent placement.

Conclusions: In the treatment of distal ureteral stones by URS, not only perioperative complications, prolongation of the operation time, and the presence of residual stones but also preoperative factors, such as systemic disease, and impacted ureteral stones should be considered as predictive factors in assessing the need for a ureteral $\mathrm{J}$ stent and to avoid unnecessary stent procedures. Keywords: Distal ureteral stone, Double J stent, Ureterolithiasis, Ureteroscopy

Cite this article as: Sahin MO, Sen V, Irer B, Yildiz G. Predictive factors for requirement of ureteral J stenting in ureteroscopic treatment of distal ureteral stones. Arch Iran Med. 2021;24(7):542-547. doi: 10.34172/aim.2021.77
\end{abstract}

Received: November 4, 2019, Accepted: May 5, 2021, ePublished: July 1, 2021

\section{Introduction}

It is estimated that urolithiasis occurs in approximately $15 \%$ of the population, and it is known that ureteral stones are responsible for $20 \%$ of all urolithiasis cases. ${ }^{1}$ The main methods used in the treatment of ureteral stones can be summarized as medical expulsive therapy (MET) that facilitate the spontaneous passage of the stone, extracorporeal shock wave lithotripsy (SWL) for stone fragmentation, ureteroscopy (URS), and open or laparoscopic procedures at lower rates. With the advances in technology, the use of URS in the treatment of ureteral stone disease has been gradually increasing. ${ }^{2}$ In complicated cases and URS procedures that leave residual stones, a urethral J stent is placed to provide urine drainage and prevent obstruction and stenosis. In the literature, the use of ureteral J stents was first described by Finney and Happerlen in 1978.,4 Ureteral J stents can have unwanted outcomes that reduce the quality of life, such as hematuria, dysuria, flank pain, urgency, frequent need for micturition, vesicoureteral reflux, infection, and stent petrification or migration. In addition, stents that are not equipped with an extraction string to facilitate removal require a second, painful intervention (e.g. cystoscopy), incurring extra costs. ${ }^{5,6}$ Therefore, rather than their routine use after URS, it is considered more appropriate to use ureteral J stents in selected cases. ${ }^{7}$ For this purpose, preoperative and perioperative factors should be taken into consideration to identify the patients who require a ureteral J stent in URS to prevent unnecessary procedures and costs.

In this study, we aimed to investigate the factors predicting the need for ureteral J stent placement in the treatment of distal ureteral stones by URS.

\section{Patients and Methods}

Patients

This retrospective study started with the approval obtained from the local ethics committee. Between January 2007 and June 2018, we evaluated the demographic data, history of urinary stone disease, data of current ureteral stone, and operation results of 550 consecutive patients who underwent URS with the diagnosis of distal ureteral stone disease in a single center. The ureteral segment diagonally below the iliac vein was considered as the distal ureter. The patients were divided into two groups: Group 1 who received a ureteral J stent, and group 2 without ureteral 
J stent. Non-contrast computed tomography (NCCT), intravenous urography (IVU) or ultrasonography (USG) and direct urinary system radiography (KUB) were used for the diagnosis of ureteral stones. In calculating the stone area, the result obtained by multiplying the stone's maximum width and length in $\mathrm{mm}$ was recorded as $\mathrm{mm}^{2}$. For the calculation of the NCCT Hounsfield unit (HU), the arithmetic mean of three different measurements was taken. Diclofenac tablets $(50 \mathrm{mg} / \mathrm{d})$ were administered orally as an analgesic on preoperative days. In patients who were found to have a urinary infection, URS was performed after appropriate antibiotic treatment when the urine was sterile. Antibiotic prophylaxis was given with third-generation cephalosporin 30 minutes before the operation. All procedures were undertaken by experienced urologists. No postoperative alpha receptor blocker or antimuscarinic drugs were administered to any of the patients. For control evaluations, KUB, USG or NCCT were used. A semi-rigid ureteroscope (Wolf, 8/9.8 Fr. $-12^{0}$ ) was utilized in the operations. In cases where balloon dilatation was required, after temporarily switching to a semi-rigid 8.5/11.5 Fr. $12^{0}$ Wolf ureteroscope, the procedure was continued with the $8 / 9.8$ Fr. ureteroscope. A pneumatic (Swiss LithoClast ${ }^{\circledR}$ Master, EMS) or laser (VersaPulse ${ }^{\circledast}$ P20, Lumenis) lithotripter was used to crush the stones. For the dilatation process, 12/15 Fr. $-4 \mathrm{~cm}$ balloons inflated at 20 atmospheric pressure for 2-5 minutes (Uromax Ultra ${ }^{\bowtie}$, Boston Scientific) were utilized. The guide wire used was a $0.38 \mathrm{~F}$ hydrophilic type (Sensor, Cook Medical or Zebra’, Boston Scientific). A 16 Fr. 2-way Foley catheter was postoperatively inserted, which was removed on the first postoperative day in most cases. A 4.7 Fr. ureteral J stent (Plasti-med) was placed in all patients presenting with iatrogenic trauma, edema findings, and residual stones in the ureter. The stone-free status was defined as being stone-free endoscopically or having stone fragments of $<2 \mathrm{~mm}$ radiologically.

The negative (stoneless) URS cases in whom no stone was detected, and the patients with multiple stones, simultaneous bilateral ureteral stones or a solitary kidney were excluded from the study.

The two groups were compared in terms of possible preoperative, perioperative and postoperative risk factors.

\section{Statistical Analysis}

Analysis of data was performed with the Statistical Package for the Social Sciences (SPSS, Inc., Chicago IL), version 22 for Windows. The Kolmogorov-Smirnov and ShapiroWilk tests were used to evaluate the normal distribution of continuous variables. Since the $P$ value was $<0.05$, these parameters were not distributed normally and MannWhitney $U$ test was used for comparison of the groups. For comparison of categorical parameters, large expected cell counts were evaluated using the chi-square test. None of the cells had a large expected cell count less than 5 in all chi-square evaluations. To control the effects of variables and isolate the relationship of double-J stenting, we used the proper statistical tools (binary logistic regression model). For model building, patient demographics and clinical data that may play a role in inserting a double-J stent such as the patient's stone disease treatment methods (ESWL and Surgical history), stone properties (stone area, CT-HU value and impacted stone) and duration of surgery were evaluated using univariate regression analysis. Then, variables with an alpha level less than 0.2 on univariate analysis were analyzed with multivariate logistic regression. Backward stepwise selection was used to refine the model with a threshold $P$ value of 0.05 for including variables in the last predictive model. The Hosmer and Lemeshow statistics were used for checking data matching and goodness of fit with the model. In all tests, $P$ value $<0.05$ was considered significant.

\section{Results}

A total of 550 consecutively presenting patients, 391 males (71.1\%) and 159 females (28.9\%), were included in the study. The mean age of these patients was $44.1 \pm 14.8$ years, the mean body mass index (BMI) was $26.4 \pm 3.2 \mathrm{~kg} /$ $\mathrm{m}^{2}$, the median stone area was $49.0 \mathrm{~mm}^{2}(36.0-100.0)$, and the median operation time was $30.0(20.0-45.0)$ minutes. A postoperative stone-free rate of $98.0 \%$ was achieved (Table 1).

There were 55 males (67.9\%) and 26 females (32.1\%) in group 1, and 336 males (71.6\%) and 133 females (28.4\%) in group $2(P=0.493)$. There was no significant difference between the two groups in terms of BMI, history of stone surgery, preoperative pain, and ureteral balloon dilatation ( $P=0.529, P=0.148, P=0.395$ and $P=0.960$, respectively). The history of systemic disease was significantly higher in group $1(39.5 \%$ vs $11.5 \%, P<0.001)$. Similarly, the history of stone disease and that of SWL were significantly higher in group 1 ( $P=0.009$ and $P=0.016$, respectively). Dilatation in the collecting system was $80.2 \%$ in group 1 and lower in group 2 at $61.0 \%(P<0.001)$. The median stone area was $64.0 \mathrm{~mm}^{2}(49.0-100.0)$ in group 1 and $49.0 \mathrm{~mm}^{2}(36.0-100.0)$ in group 2, and the difference was statistically significant $(P=0.003)$. The $\mathrm{HU}$ values calculated on NCCT were higher in group 1 than group 2 $(P<0.001)$. The operation time was longer in group 1 who also underwent ureteral J stent placement $(P<0.001)$. For fragmentation of stones, laser was more commonly used in group $1(42.0 \%)$ and pneumatic lithotripter in group $2(84.4 \%)(P<0.001)$. The rate of impacted stones was higher in group $1(61.7 \%$ vs $15.6 \% ; P<0.001)$. Analgesic use was also higher in the ureteral J stent group $(29.6 \%$ vs $9.4 \% ; P<0.001)$. Group 1 had a longer hospitalization time compared to group $2(P=0.008)$. In terms of complications, in group 1, ureteral perforation was detected in one patient and residual stones were found in 11 patients (migration in three, residual fragments in four, and stenosis in another four for whom it was not possible to reach the stone) whereas in group 2, urosepsis developed in 12 patients, arrhythmia in two, headache in one, and urinoma in one, indicating a statistically 
Table 1. General Demographics and Clinical Data

\begin{tabular}{|c|c|c|c|}
\hline & Mean \pm SD & Median & $\begin{array}{c}\text { Interquartile Range } \\
\text { Q1-Q3 (percentiles } 25 \text { and 75) }\end{array}$ \\
\hline Age (y) & $44.1 \pm 14.8$ & & \\
\hline $\mathrm{BMI}\left(\mathrm{kg} / \mathrm{m}^{2}\right)$ & $26.4 \pm 3.2$ & & \\
\hline Stone area $\left(\mathrm{mm}^{2}\right)$ & $69.6 \pm 56.0$ & 49.0 & $36.0-100.0$ \\
\hline CTHU & $695.3 \pm 379.0$ & 621.5 & 400.0-938.0 \\
\hline Operation time (min) & $33.4 \pm 20.3$ & 30.0 & $20.0-45.0$ \\
\hline Hospitalization time (days) & $1.3 \pm 1.3$ & 1.0 & $1.0-1.0$ \\
\hline & \multicolumn{3}{|c|}{ No. $(\%)$} \\
\hline \multicolumn{4}{|l|}{ Gender } \\
\hline Male & \multicolumn{3}{|c|}{$391(71.1 \%)$} \\
\hline Female & \multicolumn{3}{|c|}{$159(28.9 \%)$} \\
\hline \multicolumn{4}{|l|}{ Systemic disease } \\
\hline Absent & \multicolumn{3}{|c|}{$464(84.4 \%)$} \\
\hline Present & \multicolumn{3}{|c|}{$86(15.6 \%)$} \\
\hline Stone-free rate & \multicolumn{3}{|c|}{$539(98.0 \%)$} \\
\hline
\end{tabular}

BMI, Body mass index; CTHU, Computed tomography Hounsfield unit.

significant difference $(P<0.001)$. No patient in group 2 had any residual stones (Table 2 ).

In the multivariate logistic regression model, comorbidities, presence of impacted ureteral stone, and prolongation of the operation time were found to be statistically significant in predicting ureteral J stent placement (Table 3).

\section{Discussion}

Today, URS is frequently used in the treatment of ureteral stones, and many centers commonly apply a ureteral J stent after this procedure. Ureteral J stent placement after URS aims to reduce the incidence of renal colic due to ureteral edema, help spontaneous passage of stone fragments, accelerate postoperative healing, reduce the incidence of ureteral stenosis, and prevent postoperative ureteral obstruction. ${ }^{8-10}$ However, after ureteral J stent placement, patients may have complaints such as hematuria, migration, encrustation, stent rupture, urinary infection, and irritative voiding symptoms. ${ }^{10}$ With improvements in technology, URS has become easier to perform, reducing routine placement of a ureteral $J$ stent after the procedure and making it questionable whether it is really necessary. Researchers suggest that ureteral stent placement is not required routinely after uncomplicated ureteroscopic lithotripsy. ${ }^{11,12}$ However, a meta-analysis revealed that there was no consensus in the literature concerning the indications of ureteral stenting during the treatment of ureteral stones. ${ }^{13}$

In a multicenter study, Muslumanoglu et al reported that ureteral J stent placement after URS in ureteral stones was associated with intraoperative complications, impacted stones, operation time, stone burden, age, presence of a solitary kidney, and the stone-free rate. ${ }^{14}$ According to the multivariate analysis of the current study; the presence of systemic disease, prolonged operation time, and impacted stones were identified as potential risk factors for the requirement of a ureteral J stent.

In the presence of systemic diseases, the clinical picture of urinary system stone disease may be affected, diagnosis may be delayed, and complication rates may increase. ${ }^{15}$ Choi et al demonstrated that diabetes mellitus delayed urinary stone excretion due to the complications of vasculopathy and neuropathy. ${ }^{16}$ Similarly, in our study, ureteral J stent placement rates were significantly increased in the presence of systemic diseases.

There are publications suggesting that SWL can cause damage to the kidney, ureter, and surrounding organs. ${ }^{17-22}$ After performing SWL for the treatment of ureteral stones, Mustafa et al showed that there were increased numbers of transitional cells and mucosal layer damage in the cytology examination of urine. ${ }^{18}$ Experimental studies have also indicated that in rabbits, reversible cellular and subcellular damage occurs in the ureter mucosa, and ureter contractility is affected after SWL. ${ }^{17,19}$ Similar results are reported in other studies revealing that SWL causes tissue edema, tissue damage and decreased blood flow in target organs, and triggers inflammatory events, causing the release of oxidants, prostaglandins, COX2 and TNF- $\alpha .^{20-22}$ It can also be considered that the URS procedure may create difficulties after the reactionary responses of the ureter to SWL. ${ }^{23}$ This can also explain the increase in the need for ureteral J stent placement in our patients with SWL history on univariate analysis. However, this significance disappeared on multivariate analysis.

It is suspected that the rate of ureteral edema, hydronephrosis, hydroureter, and mucosal damage increases with longer operation time, resulting in postoperative pain. ${ }^{24,25}$ Evaluating 329 outpatients who 
Table 2. Comparison of the Demographic and Clinical Data between the Ureteral J Stent and No Stent Groups in Endoscopic Treatment of Ureteral Stones (Univariate Analysis)

\begin{tabular}{|c|c|c|c|c|c|}
\hline & & $\begin{array}{c}\text { Group } 1 \\
\text { Ureteral J Stent } \\
(\mathbf{n}=\mathbf{8 1})\end{array}$ & & $\begin{array}{l}\text { Group } 2 \\
\text { No Stent } \\
(n=469)\end{array}$ & $P$ Value \\
\hline & Median & $\begin{array}{c}\text { Interquartile Range } \\
\text { Q1-Q3 (Percentiles 25 and 75) }\end{array}$ & Median & $\begin{array}{l}\text { Interquartile Range Q1-Q3 } \\
\text { (Percentiles } 25 \text { and 75) }\end{array}$ & \\
\hline Age (years) & 49.0 & $36.5-56.5$ & 41,0 & $32.0-54.0$ & 0.022 \\
\hline BMI & 26.4 & $24.1-29.4$ & 26.0 & $24.1-27.7$ & 0.522 \\
\hline Stone area $\left(\mathrm{mm}^{2}\right)$ & 64.0 & $49.0-100,0$ & 49.0 & $36.0-100.0$ & $<0.001$ \\
\hline Stone CTHU & 846.0 & $483.8-1164,3$ & 571.0 & $381.5-887.0$ & $<0.001$ \\
\hline Operation time (min) & 45.0 & $32.0-60.0$ & 25.0 & $20.0-40.0$ & 0.002 \\
\hline \multirow[t]{2}{*}{ Hospitalization time (days) } & 1.0 & $1.0-2.0$ & 1.0 & $1.0-1.0$ & $<0.001$ \\
\hline & & $\begin{array}{c}\text { Group } 1 \\
\text { Ureteral J stent } \\
(\mathrm{n}=\mathbf{8 1}), \text { No. }(\%)\end{array}$ & & $\begin{array}{c}\text { Group } 2 \\
\text { No stent } \\
(\mathrm{n}=469), \text { No. }(\%)\end{array}$ & $P$ Value \\
\hline Gender & & & & & 0.493 \\
\hline Male & & $55(67.9 \%)$ & & $336(71.6 \%)$ & \\
\hline Female & & $26(32.1 \%)$ & & $133(28.4 \%)$ & \\
\hline Systemic disease history & & & & & $<0.001$ \\
\hline No & & $49(60.5 \%)$ & & $415(88.5 \%)$ & \\
\hline Yes & & $32(39.5 \%)$ & & $54(11.5 \%)$ & \\
\hline Stone disease history & & & & & 0.009 \\
\hline No & & $28(34.6 \%)$ & & $301(64.2 \%)$ & \\
\hline Yes & & $53(65.4 \%)$ & & $168(35.8 \%)$ & \\
\hline SWL history & & & & & 0.016 \\
\hline No & & $69(85.2 \%)$ & & $434(92.5 \%)$ & \\
\hline Yes & & $12(14.8 \%)$ & & $35(7.5 \%)$ & \\
\hline
\end{tabular}

Table 3. Outcomes of Multivariate Analysis for Potential Risk Factors Associated with Double J Stenting

\begin{tabular}{lccc}
\hline & OR & $\mathbf{9 5} \% \mathbf{C l}$ & $\boldsymbol{P}$ Value \\
\hline Age (y) & 1.01 & $0.99-1.04$ & 0.375 \\
Comorbidities & 4.12 & $1.67-10.18$ & 0.002 \\
\hline Stone disease history & 0.95 & $0.43-2.10$ & 0.908 \\
\hline Previous SWL history & 2.80 & $0,95-8.30$ & 0.063 \\
\hline Urinary tract dilatation & 1.62 & $0.73-3.63$ & 0.235 \\
Stone area (mm $)$ & 0.99 & $0.99-1.01$ & 0.715 \\
Hounsfield Unit & 1.00 & $0.99-1.00$ & 0.888 \\
Operation time (min) & 1.04 & $1.02-1.06$ & $<0.001$ \\
Lithotripter type & 1.70 & $0.79-3.67$ & 0.173 \\
(pneumatic) & 8.14 & $3.95-16.76$ & $<0.001$ \\
Impacted ureteral stone & 1.15 & $0.40-3.30$ & 0.791 \\
\hline Stone surgery history & & &
\end{tabular}

underwent URS, Cheung et al reported increased pain and complications in cases where the operation time was longer than 60 minutes and in those who received a ureteral stent. ${ }^{24}$ In another study, El-Faqih et al found that dysuria and pain were associated with ureteral stenting in $79 \%$ and $29 \%$ of the patients, respectively. The authors concluded that long operation time was associated with early postoperative pain. ${ }^{25}$ In the current study, the operation time of the ureteral J stent group was longer and it appeared as one of the predictive factors for ureteral J stent placement according to the results of the multivariate analysis.

It has been reported that impacted stones do not only affect spontaneous passage rates but also increase URS complications and reduce operative success. ${ }^{26,27}$ Sarica et al showed that a thicker ureteral wall increased the rate of ureteral J stent placement, extended the operation time, and contributed to the development of complications in the operation site. ${ }^{28}$ Similarly, we found that impacted stones were one of the predictive parameters for ureteral J stent placement.

In the literature, the general complication rates of URS are reported to vary from $5 \%$ to $9 \%$, and the rate of serious complications is around $1 \% \cdot{ }^{9,29,30}$ As a result of the latest technological developments, the miniaturization of the instruments used in endourological procedures and the small calibrations of the energy probes (e.g., holmium: YAG laser) have significantly reduced the procedurerelated morbidities. In our study, ureteral perforation only developed in one patient. Ureteral J stents were used in patients with residual fragments and the only case who developed perforation. All patients with such complications were excluded from the multivariate analysis because ureteral J stents were required. 
It is argued that when there is inadequate data for the identification of risk factors and outcomes, odds ratio (OR) and its $95 \%$ CI could be biased..$^{31}$ As a result, the OR tends to be inflated and its CI tends to be inappropriately wide. Such bias is known as sparse data bias and it can exaggerate the results of the multivariable analysis. ${ }^{31}$ In our study, sparse-date bias was observed for two risk factors (comorbidities and impacted ureteral stone) that we used in multivariate analysis.

The main limitation of this study is related to its retrospective nature. In addition, despite being a singlecenter study, the procedures were not performed by a single surgeon. Another limitation of our study was due to the retrospective design; stepwise selection subjected to estimation bias. In our study, the estimates were large due to sparse data. However, the strength of this study is that the number of evaluated patients was relatively high.

In conclusion, in the treatment of distal ureteral stones by URS, not only perioperative complications, prolongation of the operation time, and the presence of residual stones but also preoperative factors, such as systemic disease, and impacted ureteral stones should be considered as predictive factors in assessing the need for a ureteral J stent and to avoid unnecessary stent procedures.

\section{Authors' Contributions}

MOS: Project development, data collection, manuscript writing, final approval of the version to be published. VS, BI and GY: Data collection, manuscript writing, final approval of the version to be published.

\section{Ethical Statement}

Ethical approval for this study was obtained from the local ethics committee (number of the document: 49109414/806.02.02/1097 - date: 29.01.2019).

\section{Conflict of Interest Disclosures}

The authors declare that they have no conflict of interest.

\section{Funding}

This research did not receive any specific grant from any funding agency in the public, commercial or not-for-profit sector.

\section{Acknowledgments}

None declared.

\section{References}

1. Dellabella M, Milanese G, Muzzonigro G. Randomized trial of the efficacy of tamsulosin, nifedipine and phloroglucinol in medical expulsive therapy for distal ureteral calculi. J Urol. 2005;174(1):167-72. doi: 10.1097/01. ju.0000161600.54732.86.

2. Heers H, Turney BW. Trends in urological stone disease: a 5-year update of hospital episode statistics. BJU Int. 2016;118(5):785-9. doi: 10.1111/bju.13520.

3. Finney RP. Experience with new double J ureteral catheter stent. J Urol. 1978;120(6):678-81. doi: 10.1016/s00225347(17)57326-7.

4. Hepperlen TW, Mardis HK, Kammandel H. Selfretained internal ureteral stents: a new approach. J Urol.
1978;119(6):731-4. doi: 10.1016/s0022-5347(17)57613-2.

5. Fröhlich M, Fehr J, Sulser T, Eberli D, Mortezavi A. Extraction strings for ureteric stents: is there an increased risk for urinary tract infections? Surg Infect (Larchmt). 2017;18(8):936-40. doi: 10.1089/sur.2017.165.

6. Barnes KT, Bing MT, Tracy CR. Do ureteric stent extraction strings affect stent-related quality of life or complications after ureteroscopy for urolithiasis: a prospective randomised control trial. BJU Int. 2014;113(4):605-9. doi: 10.1111/ bju. 12541 .

7. Moon TD. Ureteral stenting--an obsolete procedure? J Urol. 2002;167(5):1984.

8. Anagnostou T, Tolley D. Management of ureteric stones. Eur Urol. 2004;45(6):714-21. doi: 10.1016/j.eururo.2003.10.018.

9. Roberts WW, Cadeddu JA, Micali S, Kavoussi LR, Moore RG. Ureteral stricture formation after removal of impacted calculi. J Urol. 1998;159(3):723-6.

10. Knudsen BE, Beiko DT, Denstedt JD. Stenting after ureteroscopy: pros and cons. Urol Clin North Am. 2004;31(1):173-80. doi: 10.1016/s0094-0143(03)00091-0.

11. Ateş F, Adayener C, Akyol İ, Karademir K, Şenkul T, Koçoğlu H, et al. Do I Always Need to Insert a Urethral Stent After Ureteroscopic Lithotripsy? Med J Bakirkoy. 2010;6:142-7.

12. Cevik I, Dillioglugil O, Akdas A, Siegel Y. Is stent placement necessary after uncomplicated ureteroscopy for removal of impacted ureteral stones? J Endourol. 2010;24(8):1263-7. doi: 10.1089/end.2009.0153.

13. Wang H, Man L, Li G, Huang G, Liu N, Wang J. Metaanalysis of stenting versus non-stenting for the treatment of ureteral stones. PLoS One. 2017;12(1):e0167670. doi: 10.1371/journal.pone.0167670.

14. Muslumanoglu AY, Fuglsig S, Frattini A, Labate G, Nadler RB, Martov A, et al. Risks and benefits of postoperative double-J stent placement after ureteroscopy: results from the clinical research office of Endourological Society Ureteroscopy Global Study. J Endourol. 2017;31(5):446-51. doi: 10.1089/end.2016.0827.

15. Gayer G, Zissin R, Apter S, Garniek A, Ramon J, Kots E, et al. Urinomas caused by ureteral injuries: CT appearance. Abdom Imaging. 2002;27(1):88-92. doi: 10.1007/s00261001-0052-5.

16. Choi T, Yoo KH, Choi SK, Kim DS, Lee DG, Min GE, et al. Analysis of factors affecting spontaneous expulsion of ureteral stones that may predict unfavorable outcomes during watchful waiting periods: what is the influence of diabetes mellitus on the ureter? Korean J Urol. 2015;56(6):455-60. doi: 10.4111/kju.2015.56.6.455.

17. Senyucel MF, Boybeyi O, Ayva S, Aslan MK, Soyer T, Demet AI, et al. Evaluation of contralateral kidney, liver and lung after extracorporeal shock wave lithotripsy in rabbits. Urolithiasis. 2013;41(5):431-6. doi: 10.1007/s00240-0130574-7.

18. Mustafa M, Pancaroglu K. Urine cytology to evaluate urinary urothelial damage of shock-wave lithotripsy. Urol Res. 2011;39(3):223-7. doi: 10.1007/s00240-010-0339-5.

19. Kirkali Z, Esen AA, Hayran M, Gencbay A, Gidener S, Güven $H$, et al. The effect of extracorporeal electromagnetic shock waves on the morphology and contractility of rabbit ureter. J Urol. 1995;154(5):1939-43.

20. Horgan PG, Hanley D, Burke J, Couse NF, Fitzpatrick JM. Extracorporeal shock wave lithotripsy induces the release 
of prostaglandins which increase ureteric peristalsis. Br J Urol. 1993;71(6):648-52. doi: 10.1111/j.1464-410x.1993. tb16058.x.

21. Clark DL, Connors BA, Evan AP, Handa RK, Gao S. Effect of shock wave number on renal oxidative stress and inflammation. BJU Int. 2011;107(2):318-22. doi: 10.1111/j.1464-410X.2010.09311.x.

22. Lildal SK, Nørregaard R, Andreassen KH, Christiansen FE, Jung $\mathrm{H}$, Pedersen MR, et al. Ureteral access sheath influence on the ureteral wall evaluated by cyclooxygenase- 2 and tumor necrosis factor- $\alpha$ in a porcine model. J Endourol. 2017;31(3):307-13. doi: 10.1089/end.2016.0773.

23. Irer B, Sahin MO, Erbatu O, Yildiz A, Ongun S, Cinar O, et al. Impact of previous SWL on ureterorenoscopy outcomes and optimal timing for ureterorenoscopy after SWL failure in proximal ureteral stones. World J Urol. 2020;38(3):76974. doi: 10.1007/s00345-019-02809-4.

24. Cheung MC, Lee F, Leung YL, Wong BB, Chu SM, Tam PC. Outpatient ureteroscopy: predictive factors for postoperative events. Urology. 2001;58(6):914-8. doi: 10.1016/s0090-4295(01)01445-5.

25. El-Faqih SR, Shamsuddin AB, Chakrabarti A, Atassi R, Kardar AH, Osman MK, et al. Polyurethane internal ureteral stents in treatment of stone patients: morbidity related to indwelling times. J Urol. 1991;146(6):1487-91. doi: 10.1016/s0022-5347(17)38146-6.

26. Morgentaler A, Bridge SS, Dretler SP. Management of the impacted ureteral calculus. J Urol. 1990;143(2):263-6. doi: 10.1016/s0022-5347(17)39928-7.

27. Elganainy E, Hameed DA, Elgammal M, Abd-Elsayed AA, Shalaby M. Experience with impacted upper ureteral stones; should we abandon using semirigid ureteroscopes and pneumatic lithoclast? Int Arch Med. 2009;2(1):13. doi: 10.1186/1755-7682-2-13.

28. Sarica K, Eryildirim B, Akdere H, Camur E, Sabuncu K, Elibol O. Could ureteral wall thickness have an impact on the operative and post-operative parameters in ureteroscopic management of proximal ureteral stones? Actas Urol Esp (Engl Ed). 2019;43(9):474-9. doi: 10.1016/j. acuro.2018.10.003.

29. Schuster TG, Hollenbeck BK, Faerber GJ, Wolf JS Jr. Complications of ureteroscopy: analysis of predictive factors. J Urol. 2001;166(2):538-40. doi: 10.1016/s00225347(05)65978-2.

30. Turk TM, Jenkins AD. A comparison of ureteroscopy to in situ extracorporeal shock wave lithotripsy for the treatment of distal ureteral calculi. J Urol. 1999;161(1):45-7.

31. Greenland S, Mansournia MA, Altman DG. Sparse data bias: a problem hiding in plain sight. BMJ. 2016;352:i1981. doi: 10.1136/bmj.i1981. 